\title{
Inovações disruptivas e as transformações da saúde pública na era digital
}

\author{
Disruptive innovations and transformations in \\ public health in the digital age
}

\section{Innovaciones disruptivas y las transformaciones de la salud pública en la era digital}

\author{
Onicio Batista Leal Neto 1,2 \\ Jones Albuquerque 1,3 \\ Wayner Vieira Souza 4 \\ Eduarda Cesse 4 \\ Oswaldo Gonçalvez Cruz 5
}

doi: 10.1590/0102-311X00005717

Cada vez torna-se mais evidente a mudança de toda a sociedade na era da informação, com mais pessoas conectadas e com acesso às tecnologias e à Internet mais abundante, gerando uma produção intensa e coletiva de informação ${ }^{1}$. No campo da saúde pública, uma das áreas que se apresenta em franca expansão é a chamada detecção digital de doenças (DDD) 2, que aproveita o movimento da popularização da Internet e sociedade em rede para a identificação oportuna de ameaças à saúde pública. Em uma perspectiva aplicada aos sistemas de informação em saúde no âmbito do Sistema Único de Saúde (SUS), por enquanto a DDD vem sendo utilizada de modo complementar, porém, em um futuro muito próximo, como é mais ubíqua, estará mais presente que os atuais sistemas de informação.

É bem certo que tecnologias sempre estiveram presentes como instrumentos de melhoria à saúde. Há mais de duas décadas, os sistemas de informação já se fazem presentes em diversos países, como em sistemas de informações vitais ou de morbidade ${ }^{3}$. São evidentes os esforços de estudos e pesquisas na área da saúde digital que continuaram evoluindo, seja nos componentes dos hospitals information systems 4 , seja na instrumentalização tecnológica da assistência à saúde nos prontuários eletrônicos 5 .

A questão que este texto apresenta é a necessidade do olhar para as tecnologias de crescimento exponencial (drones, Internet of things, crowdsourcing, economia compartilhada, wearables e medicina personalizada, dentre outras). O foco é como elas irão criar as disrupções nos paradigmas das ciências da saúde pela via da análise massiva de dados e das tecnologias da informação e comunicação, com a qual estamos acostumados a lidar no âmbito de pesquisas ou serviços relacionados ao SUS.

Essa não é uma questão exclusiva das ciências da saúde, visto que as ciências sociais e até as ciências exatas estão sob a luz do ciclo de vida social da informação na sociedade. De fato, as ciências têm se transformado cotidianamente com as inovações e com os cenários gerados. Ademais, deve-se levar em conta como os indivíduos, nós, as percebemos para explicarmos os fenômenos que nos rodeiam e suas modificações, como previsto há quase duas décadas 6 . Assim, o objetivo desse texto é provocar uma discussão e assumir algumas perspectivas desse movimento que surgiu liderado pela área da informática, ligada diretamente com a evolução das inovações disruptivas 7 no tratamento do ciclo de vida da informação quando aplicado às ciências da saúde. O destaque da narrativa a ser apresentada a seguir engloba aspectos ainda pouco frequentes em discussões no âmbito nacional dos fóruns de informática ou sistemas de informação em saúde, não obstante sendo de elevado interesse à ótica dos especialistas em saúde para esse movimento.
${ }^{1}$ Epitrack, Recife, Brasil. 2 Singularity University Recife Chapter, Recife, Brasil. ${ }^{3}$ Laboratório de

Imunopatologia Keizo Asami, Universidade Federal de Pernambuco, Recife, Brasil. ${ }_{4}^{4}$ Centro de Pesquisas Aggeu Magalhães, Fundação Oswaldo Cruz, Recife, Brasil. 5 Fundação Oswaldo Cruz, Rio de Janeiro, Brasil.

Correspondência O. B. Leal Neto Epitrack.

Rua Alfredo Coutinho 74, 2o andar, Recife, $P E$ 52061-130, Brasil. onicio@gmail.com 
Com as premissas estabelecidas na conhecida Lei de Moore e corroboradas na Lei dos Retornos Acelerados 8, o crescimento exponencial das tecnologias e seu papel na sociedade é cada vez mais indispensável e irrevogável. Ao observar o modelo estrutural das inovações exponenciais ${ }^{9}$, nominadas por seis "Ds" (digitalizado, disfarçado, desmonetizado, desmaterializado, disruptivo e democratizado), é possível confrontá-lo com a estrutura atual existente nos sistemas de informação em saúde no SUS. Se, por um lado, observa-se a dura realidade dos estados, municípios e Ministério da Saúde em manter toda a infraestrutura tecnológica e computacional com licenças, manutenção, desenvolvimento, segurança e treinamento, por outro lado, o futuro da coleta, armazenamento, análise de dados e produção da informação vem comprovando que o que é feito atualmente não possui escalabilidade para atender a toda a população em grau individual e, portanto, sem sustentabilidade.

Se municípios ainda coletam dados dos agentes comunitários de saúde com pranchetas ou a tabulação dos dados para o Sistema de Informação de Agravos de Notificação (SINAN) não atende a todas as necessidades e expectativas, há urgência na revisão desses procedimentos. A angústia de tratar os dados e informações considerando os meios obsoletos é real, pois há carência imediata da incorporação tecnológica para diminuir o ciclo de vida da informação e aprimorar os meios utilizados para que a máxima "informação para ação" se torne uma realidade na saúde do Brasil.

Atualmente, diversos países têm investido massivamente em Inteligência Artificial, Aprendizado de Máquina e Aprendizado Profundo como tendências que vão auxiliar cada vez mais a tomada de decisão em saúde. Um estudo 10 demonstra um ensaio contundente da aplicação de inteligência cognitiva sobre o IBM Watson em desfechos para a saúde, mostrando toda a potencialidade dessa abordagem computacional em processos de rotina.

Já vivemos na era do big data, em que não bastam apenas meios para armazenar e processar volumes grandiosos dos dados em saúde. É tempo de provocarmos a necessidade de visualizar melhor esse conhecimento, que pode ser extraído de bases extensas onde estão bancos de dados clássicos provenientes dos sistemas de informação conhecidos do SUS, e, para serem mais efetivos, devem ser cada vez mais compostos por dados vindos das redes sociais, dispositivos móveis geolocalizados, Internet das Coisas 5 e Cidades Inteligentes. A sociedade está conectada, e não é por acaso que conceitos como infodemiology (information + epidemiology) e infoveillance (information + surveillance) 11 precisam ser considerados na rotina de analistas e produtores de informação em saúde.

Citaremos alguns casos reais da mudança de paradigmas dentro da saúde pública, explicitando como nós não estamos preparados para entender bem os benefícios, riscos e transformações que essas inovações disruptivas trazem para nosso contexto.

Há evidências da importância e do crescimento da vigilância participativa 12 para doenças infecciosas, sendo um processo desburocratizado, não hierarquizado e em rede, propiciando a lógica do controle social defendido pelo SUS, porém com grande influência digital, em que o cidadão comum passa a ser fonte de informação para a construção dos cenários epidemiológicos. Exemplos como Saúde na Copa, Flu Near You, Flutracking, Salud Boricua e InfluenzaNet são demonstrações de como essa metodologia de vigilância em saúde tem se disseminado ao redor do mundo ${ }^{2}$. Em alguns casos, é possível a identificação da ocorrência de surtos de influenza com até duas semanas de antecedência 13 .

O incentivo à promoção da saúde e prevenção de doenças, principalmente com o foco no estímulo à realização de exercícios físicos, evitando os riscos da obesidade, também pode ser visto nessas inovações disruptivas. A aplicação de Realidade Aumentada, embutida em jogos para smartphones, demonstra o papel que o jogo Pokémon Go teve no estímulo à prática de atividades físicas. Também é apontada a possibilidade de intervenção em larga escala, não se limitando às classes sociais, podendo gerar resultados mais promissores que os elementos de educação em saúde e prática de atividades físicas triviais 14. Esse exemplo descreve bem como a realidade aumentada está tomando parte da vida dos indivíduos, porém é necessário um cuidado para reconhecer o ponto de equilíbrio entre os benefícios e as ameaças à saúde.

Outro movimento interessante acontece na regulação e transporte de pacientes em caráter não emergencial pela utilização de plataformas como o Uber e Lyft 15. Se há limitações na mobilidade de pacientes crônicos que os impeçam de utilizar o transporte público e se não é possível familiares realizarem esse transporte, muito menos o desembolso com motoristas particulares ou simplesmente taxis, a locomoção até locais para terapia, reabilitação ou qualquer outro procedimento de ordem 
clínica-médica, esses dois aplicativos, que tanta polêmica geram no Brasil, começam a mudar a compreensão da regulação e acesso à saúde nos Estados Unidos.

Outro gargalo na era da informação é a comunicação e a educação em saúde. Vivemos há, pelo menos, uma década com investimentos massivos em publicidade para combate à dengue, infecções sexualmente transmissíveis (ISTs) e AIDS, entretanto os indicadores de morbimortalidade não decrescem proporcionalmente aos esforços financeiros empregados no controle dessas doenças. Talvez uma resposta para isso seja a forma como isso tem sido feito até então.

Por outro lado, uma ação inédita e atípica (disruptiva) para prevenção do vírus da zika foi implementada durante as Olimpíadas no Rio de Janeiro, Brasil. O site de entretenimento adulto PornHub realizou uma ação publicitária em que, se os indivíduos que estivessem no Rio durante as competições não adotassem comportamentos sexuais de risco, eles poderiam ter acesso integral ao conteúdo da plataforma de vídeos pornôs, enfatizando a melhor maneira da prevenção de transmissão sexual do zika: não existindo relação sexual 16 . Uma ação semelhante na ousadia e no ineditismo foi adotada pelo próprio Ministério da Saúde em 2015, quando utilizou os aplicativos de encontros Tinder e Hornet para ações direcionadas a usuários com comportamento de risco para ISTs 17. Recentemente, na Califórnia, Estados Unidos, cidadãos votaram sobre o uso de preservativos em filmes pornôs 18, gerando questionamentos sobre o impacto na percepção da proteção e sexo seguro após movimentos como esses.

Os relatos acima demonstram fortes indícios de que as inovações disruptivas na saúde pública estão muito mais presentes em nosso contexto nacional do que imaginamos, devido a seu potencial crescimento exponencial. Faz-se necessária a sensibilização de pesquisadores, gestores, sanitaristas e quaisquer outros atores que trafegam à luz dos dados e informação em saúde, para que seja considerado esse novo movimento em suas premissas, pesquisas e práticas de saúde coletiva. É possível ver que até o mercado privado entendeu a valia dos dados para seu movimento, e é evidente que o setor público, por mais tradicional e conservador que seja, não pode continuar demonstrando resistência à quebra do paradigma informacional.

A imensidão de dados que estão sendo gerados, tanto pelas fontes convencionais, quanto pelas novas plataformas, algumas delas mencionadas e outras a surgirem, carece de olhares mais críticos, abertos, propositivos e, sobretudo, disruptivos, a fim de incrementar o arsenal de instrumentos para a prática da saúde pública, na pesquisa ou no serviço. Contudo, é importante avaliar a capacidade de absorção e aderência que o setor público possui e quantas dessas inovações estarão passíveis de regulação para seu funcionamento dentro de preceitos éticos, garantindo a privacidade aos usuários e servindo ao interesse público. Dessa forma, o SUS poderá não só acompanhar, mas usufruir e se tornar um efetivo ator dessa rápida transformação na corrida pelo uso da informação para a melhoria da qualidade de vida de todos os cidadãos.

\section{Colaboradores}

O. B. Leal Neto participou da organização, concepção e redação do artigo. J. Albuquerque, W. V. Souza, E. Cesse e O. G. Cruz colaboraram na revisão crítica do conteúdo intelectual do artigo.
1. Brabham DC. Crowdsourcing as a model for problem solving: an introduction and cases. Convergence 2008; 14:75-90.

2. Leal-Neto OB, Dimech GS, Libel M, Oliveira W, Ferreira JP. Detecção digital de doenças e vigilância participativa: panorama e perspectivas para o Brasil. Rev Saúde Pública 2016; 50:17.

3. Baldijão MFA. Sistemas de informação em saúde. São Paulo Perspect 1992; 6:21-8. 
4. Cortes PL, Cortes EGP. Hospital information systems: a study of electronic patient records. Journal of Information Systems and Technology Management 2011; 8:131-54.

5. Roehrs A, Costa CA, Righi RD, Oliveira KS. Personal health records: a systematic literature review. J Med Internet Res 2017; 19:e13.

6. Brown JS, Duguid P. The social life of information. Brighton: Harvard Business School Press; 2002.

7. Hwang J, Christensen CM. Disruptive innovation in health care delivery: a framework for business-model. Health Aff (Millwood) 2008; 27:1329-35.

8. Kurzweil R. The law of accelerating-returns. http://www.kurzweilai.net/the-law-of-acceler ating-returns (acessado em Mar/2001).

9. Diamandis PH, Kotler S. Abundance: the future is better than you think. New York: Simon \& Schuter; 2012.

10. Hoyt RE, Snider D, Thompson C, Mantravadi S. IBM Watson analytics: automating visualization, descriptive, and predictive statistics. JMIR Public Health Surveill 2016; 2:e157.

11. Eysenbach G. Infodemiology and infoveillance: framework for an emerging set of public health informatics methods to analyze search, communication and publication behavior on the internet. J Med Internet Res 2009; 11:e11.

12. Wójcik OP, Brownstein JS, Chunara R, Johansson MA. Public health for the people: participatory infectious disease surveillance in the digital age. Emerg Themes Epidemiol 2014; 11:7.
13. Santillana M, Nguyen AT, Dredze M, Paul MJ, Nsoesie EO, Brownstein JS. Combining search, social media, and traditional data sources to improve influenza surveillance. PLoS Comput Biol 2015; 11:e1004513.

14. Althoff T, White RW, Horvitz E. Influence of Pokémon Go on physical activity: study and implications. J Med Internet Res 2016; 18:e315.

15. Power BW, Rinefort S, Jain SH. Nonemergency medical transportation delivering care in the era of Lyft and Uber. JAMA 2016; 316:921-2.

16. Cowen TW. Pornhub launches "Ooohlympics" health initiative to battle zika virus ahead of Rio Olympics. http://www.complex.com/ life/2016/08/pornhub-launches-ooohlympicshealth-initiative-zika-virus-rio-olympics (acessado em Ago/2016)

17. Blog da Saúde. Ação do Ministério da Saúde nos aplicativos Tinder e Honest surpreende usuários. http://www.blog.saude.gov.br/index. $\mathrm{php} / 570$-perguntas-e-respostas/35136-acaodo-ministerio-da-saude-nos-aplicativos-derelacionamento-tinder-e-hornet-surpreendeusuarios (acessado em Fev/2015).

18. Woodyard C. California voters reject condoms for porn actors. USA Today 2016; 8 nov. http://www.usatoday.com/story/money/ 2016/11/08/californians-vote-condom-useporn-actors/93464012/. 